\title{
How Can We Improve Disease Education in People with Gout?
}

\author{
Theodore R. Fields ${ }^{1,2} \cdot$ Adena Batterman ${ }^{3}$ \\ Published online: 8 March 2018 \\ (C) The Author(s) 2018. This article is an open access publication
}

\begin{abstract}
Purpose of Review Gout management is currently suboptimal despite excellent available therapy. Gout patient education has been shown to enhance medication adherence and self-management, but needs improvement. We explored the literature on gout patient education including gaps in gout patient knowledge; use of written materials; in-person individual and group sessions; education via nurses, pharmacists, or multi-disciplinary groups; and use of phone, web-based, mobile health app, and text messaging educational efforts.

Recent Findings Nurse-led interventions have shown significant improvement in reaching urate goals. Pharmacist-led programs have likewise succeeded, but to a lesser degree. A multi-disciplinary approach has shown feasibility. Needs-assessments, patient questionnaires, and psychosocial evaluations can enhance targeted education.

Summary An interactive and patient-centered approach can enhance gout educational interventions. Optimal programs will assess for and address educational needs related to knowledge gaps, health literacy, race, gender, socio-economic status, and level of social support.
\end{abstract}

Keywords Gout · Patient education · Self-management · Adherence $\cdot$ Crystal arthritis $\cdot$ Multi-disciplinary care

\section{Introduction}

The need for effective gout patient education is powerfully supported by the literature and medication adherence is acknowledged as a key goal in improving rheumatic disease health outcomes [1]. Fortunately, there is evidence that patients with gout can improve adherence with appropriate education [2].

Gout is common [3], has a significant negative impact on quality of life [4-6], and has an increased risk of mortality [7]. The economic burden of gout is high [8]. Current treatments for gout, if carefully prescribed and regularly taken, are effective in stopping gout flares and improving quality of life in the vast majority of patients [9-11]. All but one published gout

This article is part of the Topical Collection on Crystal Arthritis

Theodore R. Fields

fieldst@hss.edu

1 Division of Rheumatology, Hospital for Special Surgery, 535 East 70th St., Suite 848-West, New York, NY 10021, USA

2 Weill Cornell College of Medicine, New York, NY, USA

3 Department of Social Work Programs, Hospital for Special Surgery, New York, NY, USA treatment guidelines support the importance of a serum urate goal, generally $<6.0 \mathrm{mg} / \mathrm{dl}$ for those with non-tophaceous gout [12-14]. Despite these guidelines and the availability of highly effective therapies for reducing serum urate, the majority of gout patients, internationally, have poor medication adherence and fail to reach their serum urate treatment goal [15-19]. Even when appropriate prescribing and treatment practices are followed, prescriptions are often not taken as directed.

The 2017 British gout management guidelines strongly emphasized the importance of gout patient education, which should highlight key management points, such as causes and consequences of gout and hyperuricemia, lifestyle and diet, alcohol and obesity, and urate-lowering therapy (ULT) goals. These guidelines emphasize an individualized education plan, "considering co-morbidities and concurrent medications, illness perceptions and potential barriers to care" [12]. Inaccurate popular beliefs and myths about gout held by patients and physicians present barriers to appropriate patient education and treatment and need to be addressed and dispelled [20]. All of these findings indicate that quality improvement approaches in gout care "clearly start with provider and patient education" [21].

Gout patient education has been suboptimal in outpatient settings $[18,22 \bullet \bullet]$. For example, patients with gout tend to be unaware of their urate goal, which is the cornerstone of long- 
term management [23]. In the hospital setting, patients are likely to leave hospital without a urate-lowering plan [24].

Patients with gout are primarily managed by primary care physicians (PCP's), who are time-challenged and need to be kept updated on current optimal gout management strategies, especially in patients with multiple comorbidities. Rheumatologists, therefore, need to educate their primary care colleagues and other providers involved in the care of gout patients.

Patient self-management is a key part of chronic disease care [25], and structured programs to enhance selfmanagement efforts have been shown effective in arthritis [26] and in other chronic conditions [27]. The need to include families and lay caregivers in patient education to improve outcomes has been emphasized in chronic diseases, and also in gout $[28,29]$.

Recently, several gout-specific patient education interventions have been studied, including nurse- and pharmacist-led programs. A multi-disciplinary team approach to patient education has been increasingly studied [30].

The literature supports the need for a patient-centered approach to education for rheumatic diseases, including gout, which addresses the unique psychoeducational needs of individual patients [31-33]. This review will discuss the available literature on disease-specific education in people with gout and suggest directions for future research.

\section{What Do Gout Patients Need to Know? What Are Their Knowledge Gaps?}

A recent EULAR panel reviewed the literature regarding patient education interventions for people with inflammatory arthritis. The review underscored the need for an interactive, ongoing dialogue to address disease-specific information, and also the unique emotional and informational needs of each patient [34].

Gout patient disease- and treatment-related knowledge gaps have been well explored in the literature. A ten-item patient questionnaire assessing for gout disease and treatment knowledge reported a mean number of correct responses of 6.15 , with frequent incorrect responses related to use of uratelowering drugs, optimal goal urate levels and appropriate duration of ULT [35]. Similar gaps were found in other studies $[36,37]$. Knowledge gaps related to lifestyle modifications, including alcohol intake and dietary triggers for gout attacks, are also widely reported [36, 38].

A 26-item needs assessment was administered to 100 rheumatologist-treated gout patients, to obtain information about knowledge gaps, perceived self-efficacy, and patientidentified psychoeducational needs and preferences [39]. This study found that patients had difficulty understanding bridge therapy, the use of prophylaxis for gout flares during the early phase of urate-lowering therapy. They were often unaware of optimal treatment goals (e.g., "no further flares"). For example, more than $30 \%$ of study participants who had > 3 flares within the past 6 months felt that their gout was "under control." Respondents expressed the desire for additional information about managing medication side effects and dietary management, specifically from a nutritionist. This prompted inclusion of this content and a nutritionist as speaker for an upcoming community gout symposium.

Educational gaps exist for caregivers as well as patients. An online survey which looked at the impact of gout on quality of life of a large number of gout patient caregivers and patients identified these gaps (https://creakyjoints.org/goutsurvey/). Gaps included limited understanding of the role of diet and genetics in gout, and poor knowledge of the target urate goal. These findings indicate that caregiver education might enhance patient adherence and quality of life and is consistent with a recent proposed emphasis on patient- and family-centered medical education [40].

Persistent myths, such as the lack of a need for long-term ULT, have been analyzed [36] and patient education discussions should include clarifying misconceptions. These issues, as well as other barriers to optimal care unique to each patient, should be explored, not only in initial consultations but as part of an ongoing dialogue. Also, tools such as gout knowledge questionnaires can be used as initial screens to identify misconceptions and other knowledge gaps and can be useful in guiding patient-provider discussions. Several such questionnaires have been published [35-37]. Gout patients often lack knowledge of the "causes and consequences" of gout, with little appreciation that poor medication adherence leads to recurrent gout flares. Many associate gout with negative stereotypes [28] and with images portrayed in Victorian cartoons, and see their disease as self-inflicted [41]. With a lack of understanding of the genetic and metabolic aspects underlying their gout, patients might see themselves as "at fault." Patients have expressed feeling stigmatized by healthcare providers, who they believe perceive their gout as related to alcohol and dietary excess. These issues can affect patients' willingness to seek treatment or engage in open dialogue about their symptoms with providers $[42,43]$.

\section{Patient-Centered Education: Incorporating the Patient Perspective}

Research which underscores benefits of incorporating the patient's perspective in research and program initiatives is well established $[44,45]$. These studies provide insight into what symptoms, experiences, and treatment outcomes have meaning for and relevance to patients and can be used to inform content for educational interventions. Interventions should ideally emphasize issues which motivate patients to adhere to treatment based on their priorities and identify barriers to 
self-management. In rheumatoid arthritis (RA) literature, one well-designed study reported on an educational needs assessment, which asked patients to prioritize their educational needs via a questionnaire. Results were used to develop a needs-based education program, which improved participants' self-efficacy and health status [33]. Though this assessment was studied in RA patients, a similar approach might be considered to assess for patient-identified needs for individualized gout education.

Several recent qualitative studies have focused on gout patients experiences of gout and gout-related education. Khanna et al. conducted focus groups of gout patients and reported that they felt they lacked sufficient knowledge of treatment options, the progressive nature of gout, and felt that practitioners did not spend enough time with them on education [46]. Other studies report similar themes with additional disease and treatment education concerns, such as the need for warnings about increased risk of gout flares upon initiation of ULT, and lack of information about diet. Of note, patients expressed that they would have started ULT sooner, had they better understood the rationale for treatment [36, 42]. Another qualitative study looked at patient-identified core gout-related issues impacting patients' quality of life, including pain, sleep, and social activity [47].

Race and Gender: Impact on Gout Educational Needs Race and gender disparities in gout management have been explored. Krishnan looked at sociodemographic variables associated with allopurinol prescription during outpatient visits for patients with gout, and found that African Americans were less likely to receive allopurinol than Caucasians, and an even lower proportion of Asian Americans received allopurinol prescriptions [48]. African Americans have a higher prevalence of gout risk factors but, after accounting for these risk factors, have a significantly lower risk for both gout and hyperuricemia compared with Caucasians [49]. Racial differences in patient-reported quality of life, and barriers and facilitators to adherence have also been studied. For example, qualitative studies of African-American patients with gout found a number of barriers to urate-lowering therapy adherence, including cost and concerns about side effects of medication, patient preference for alternative medicines, concerns about dietary restrictions, and doubts regarding effectiveness of medication [49-51]. Facilitators to adherence included understanding of role of ULT in flare prevention, pain prevention, benefit of less dietary restrictions, and trust in physician $[50,51]$.

A large body of literature discusses the influence of culture, race, and ethnicity on patient experience of medical encounters and systems. All of these have impact on patient/provider rapport, trust, and communication, including how patients ask questions, their comfort level in raising concerns about treatment and sharing cultural perspectives about illness [52].
Discordance in race/ethnicity between provider and patient can also present challenges in patient education related to language barriers when communicating complex disease and treatment information, and, discussing gout patients' culturerelated differences in illness perceptions, self-management, and treatment [53].

Differences in impact of gout on gender have also been identified. In one study, women were especially concerned with increased dependency and joint deformities as a result of progressing gout $[38,51]$. Another study found women participants to have difficulty accepting a diagnosis of gout and finding information relevant to them, influenced by common beliefs and stereotypes that gout is a condition typically affecting men. Women in this study were likely to feel that gout had a major impact on their identity, roles, mood, and relationships and found it helpful to reach out to other women for support online [38]. Another recent study found that men with RA may be less open to support group sessions than women and suggest that genderrelated concerns, impact of illness, and preferences for support should be considered when developing strategies and interventions for education and support [54].

\section{Gout Patient Educational Interventions: Multiple Modalities}

\section{Written, Online, and Mobile Health Materials}

A review of patient information about gout, written and online, found that over half were written at a "highly complex level" and that some key areas were inadequately covered, such as comorbidity-related risks and the importance of continuing urate-lowering therapy during attacks [55]. This review also found essential self-management information such as dietary guidelines and serum urate target levels were inconsistently presented within resources. A 2013 study reviewed ten gout patient information resources and found the median readability grade level was 8.5 , and approximately one third of these resources were found to be above the average reading level of rheumatology out-patients. Sixty percent of resources lacked essential information about gout flare prophylaxis during initiation of urate-lowering therapy and treating serum urate to target [56]. A recent article emphasized the need for specific language about gout that will best help patients (and providers) understand the concepts being taught [57].

Mobile applications for gout have been developed and show promise for future interventions which use interactivity to tailor information to individual self-management needs [58]. One review [59] examined 57 English-language gout apps, 6 of which allowed patients to monitor their urate levels and gout flares along with educational materials. One included all three of these elements, but the majority did not function within the app and required users to print out and complete 
materials. A review of digital health programs to improve adherence in multiple rheumatic diseases, including gout, emphasized the need for tailored, patient-centric interventions that can focus on individual patterns of non-adherence [32]. Electronic reminders to improve adherence to chronic medications have also been reviewed. In a study of use of text (SMS) messaging, electronic reminder devices, and pagers to improve medication adherence in several medical conditions, improvement was found, especially with text messaging [60]. The optimal online program may be a combination of interactive education, documentation in a format easily shared with a health care provider and an alert system, a combination not yet available.

A number of online tools are available for gout patient education, including the Gout \& Uric Acid Education Society, http://gouteducation.org/, the American College of Rheumatology (https://www.rheumatology.org/I-Am-A/ Patient-Caregiver/Diseases-Conditions/Gout) and Hospital for Special Surgery (https://www.hss.edu/conditions_goutrisk-factors-diagnosis-treatment.asp). Further study is needed to assess the impact of these tools and their appropriate role in education and management.

\section{Individual and Group Patient Education Interventions}

Reviews of the effects of educational efforts on adherence have shown variable results, with best results found in interventions tailored to patients and delivered by a healthcare provider [29, 61]. Reviews have shown progress in overcoming barriers to gout patient education and self-management, but with more gains yet to be made [62].

\section{Individual Interventions}

A pharmacist-coordinated program reported a greater number of intervention patients reaching their goal urate of $<6.0 \mathrm{mg} /$ $\mathrm{dL}$, but this reflected only $13(35 \%)$ of the intervention patients vs. 5 (13\%) of control group patients [63]. Another group looked at pharmacist-directed phone-based gout patient education and, in a recent abstract, reported that the intervention patients reached their serum urate goal more frequently than controls, but only $31.3 \%$ of 631 intervention patients vs. $20.6 \%$ of 782 control patients reached urate $<6.0 \mathrm{mg} / \mathrm{dL}$ [64].

An observational study of a nurse-coordinated intervention showed that $92 \%$ of the 106 participants reached urate < $6.0 \mathrm{mg} / \mathrm{dL}$ at 12 months [65••]. The intervention involved a clinical assessment with a rheumatologist which included gout-related education, an individualized tailored plan addressing modifiable risks and ULT information. Ongoing follow-up with a nurse included counseling about chronic disease progression, lifestyle self-management advice, and availability for questions as needed. Five years post-intervention, persistence on ULT was $90.7 \%$, per patient-report via a questionnaire [66]. In another study, positive effects of nurseprovided drug information have also included increased patient sense of autonomy, knowledge, and trust in their caregiver [67].

Given the strong support in the literature for using a team approach to augment physician-provided gout education, our team recently reported on a pilot study of a gout education and management program which included a multi-disciplinary team of pharmacists, nurses, and a social worker [68]. The study featured a nurse-led patient education initiative and used a standardized curriculum covering gout causes, treatment, medications, urate goals, and dietary recommendations. Administration of a gout knowledge questionnaire prior to teaching was used to identify targeted content for individual counseling with a specially trained nurse. Follow-up phone calls were made monthly by pharmacists, to encourage adherence and respond to medication questions. The study supported the feasibility and acceptability of implementing a team approach to gout patient education in a busy rheumatology academic practice and suggested future controlled studies of such programs.

\section{Group Interventions}

Group interventions aimed at enhancing education and selfmanagement strategies for gout patients have not been widely reported in the literature, but have been discussed in other rheumatologic conditions with mixed results. These can, perhaps, provide guidance in creating similar gout-specific patient interventions. For example, the Arthritis SelfManagement Program (ASMP) is a well-studied, structured intervention which focuses on self-management strategies for arthritis patients, and has reported improved pain, increased disease-related knowledge, and recommended health behaviors compared to a control group patients [26]. The program has also been successfully duplicated with positive results for Spanish-speaking patients, including improved health behaviors, health status, and self-efficacy [69].

Other similar group interventions have reported improvements in depression, social and role limitations, and patientprovider communication [27]. A nurse-led patient education group intervention with a follow-up individual session was studied in patients with inflammatory arthritis. This was a 6week program which focused on problem-solving, selfmanagement skills, goal setting, and treatment options. The last 26 patients enrolled in this randomized, controlled study were interviewed before and 2 months after completion of the intervention. These patients (15 in the intervention group and 11 in the control group) in this qualitative study were questioned about their perceived coping with their arthritis. Patients in the educational intervention group, but not in the 
control group, reported strengthened confidence in managing pharmacological treatment, better coping with illness fluctuations, and positive changes in health behaviors (including improved medication adherence and dietary management). Intervention group participants attributed these improvements, in part, to the group modality; they identified the specific benefit of participating in a forum to discuss issues related to illness management and coping with peers with shared experiences [70]. While these results provide support for the value of a group modality in patient education for inflammatory arthritis, potential limitations should be kept in mind in interpreting the results. As the authors acknowledge, selection bias may have occurred with patients at initial entry into the randomized trial. Patients who felt they were coping well may have declined participation since they did not feel a need for education. Alternatively, patients with poorer coping skills may have been less able or likely to participate in an intervention which required multiple sessions and interviews. In another study which reported on patient perceptions of a cognitive behavioral therapy (CBT) group intervention for managing fatigue in RA, patients reported enhanced selfmanagement efforts [71]. Although results on the efficacy of group patient education interventions have yielded mixed results, there is sufficient evidence that suggests that further research should be conducted to determine which models might be used effectively in gout patient education and which patients would benefit.

\section{Additional Considerations}

\section{Health Literacy}

There is strong evidence to suggest that many patients do not understand disease-related information provided in written and verbal form in rheumatology medical encounters [72]. Many patients may leave a rheumatologist's office with poor recall, retaining only a small portion of the information discussed at their appointments [73]. Also, patients who are overwhelmed, anxious, or depressed have difficulty retaining and processing health-related information. Providers cannot assume patients' health literacy competency based on education level alone.

Simple brief validated screens, such as the Single Item Literacy Screen (SILS), can be used as a preliminary evaluation, to determine if a patient has literacy and language barriers or other barriers which might impact their ability to read health-related materials. Engaging all patients in bi-directional teaching, including "teach-back" techniques, can be effective in determining whether the patient has understood information, can provide an opportunity to clarify key issues, and can improve disease-related knowledge, adherence, and selfefficacy [74]. A toolkit for rheumatology healthcare providers to help address issues of health literacy can be found at http:// www.med.unc.edu/tarc/files/HLUPTRheum.pdf.

\section{Opportunities and Timing of Education}

The acuity and severity of gout flares can be powerful motivators to take preventive measures and can present a unique opportunity to discuss long-term management plans. One study reviewed charts of hospitalized patients with gout flares and found that only $36.1 \%$ had ULT initiation or dose alteration in the hospital or recommendations made to their general practitioners. This percentage increased to $82.1 \%$ if the patient was seen by the rheumatology service [24]. Similar critical patient education opportunities may occur when patients are seen for gout flare in emergency rooms or urgent care centers or by podiatrists. Both providers and patients need to see these episodes as opportunities to improve long-term prevention strategies.

Repeated educational messages (spaced learning) have been shown to be an effective strategy for memories that "stick" [75] This implies the benefit to having periodic "refresher" sessions with gout patients to remind them of the rationale for their long-term use of ULT and other key selfmanagement points. Feedback, where patients receive individualized information based on their knowledge deficits or specific questions, has been shown to improve adherence to medications [76]. This supports potential benefit of interactive knowledge questionnaires with feedback on responses, and online programs which provide education informed by individual details entered by the patient.

\section{Conclusions and Future Options}

The rewards of gout patient education in terms of improved outcomes seem clear, but much work still needs to be done. Review of the literature and our experience suggests that future optimal education for patients with gout requires a multifaceted approach (see Fig. 1). Multiple types of health care professionals have the potential to offer excellent gout patient education, either individually or in labor-dividing teams. Approaches must incorporate patient-identified needs and also ensure that specific knowledge gaps and best practice clinical management guidelines are addressed. Written or online questionnaires can help identify such gaps and have the potential to help create targeted individualized patient education. Key concepts highlighted in the literature include genetic and metabolic causes of gout, the risk of progressive damage with inadequate treatment, goal serum urate levels and why they are monitored, rationale for short- and long-term management, impact of comorbidities, and dietary management. Focus on these issues reflects partnership between patient and provider, where both 


\section{Improving disease education in people with gout}

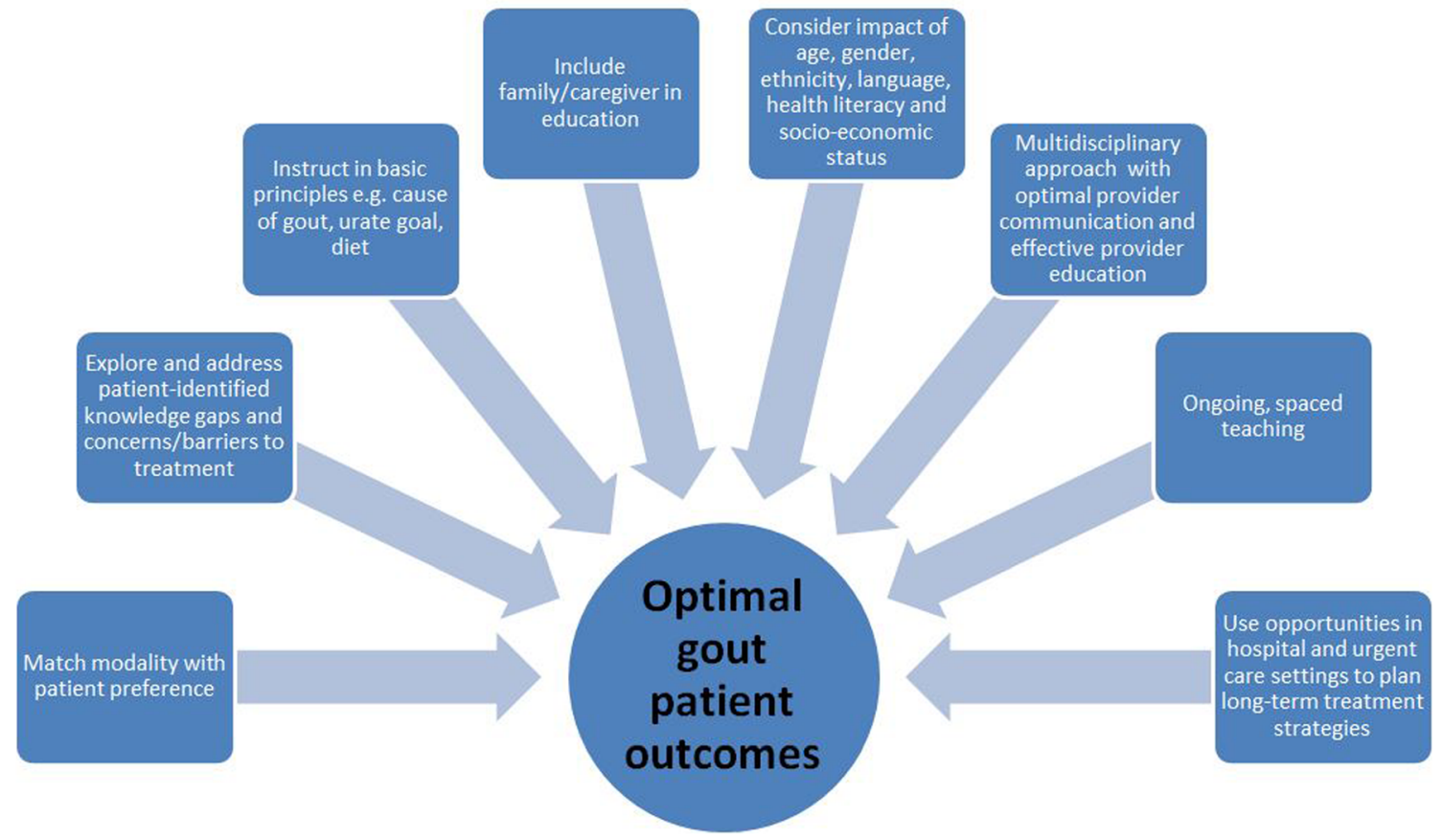

Fig. 1 Factors to consider in a patient-centered interactive approach to gout patient education

are working toward a shared concrete goal. As a team, providers must assess for possible barriers to treatment, such as ability to pay for medications and health literacy issues. Patients need to be screened for health literacy, and providers can ensure that information is well understood, using strategies such as teach-back methods [77] and reading level-appropriate materials [72]. Caregivers and family, as well as gout patients, need to be educated. This is consistent with the developing goal of patient- and family-centered medical education [40].

Also critical to improving gout patient education is addressing gout health care provider education. Efforts to improve gout management knowledge of primary care providers and other providers who are involved in gout patient care is critical to ensuring gout patients get the essential information they need to support them in their self-management efforts. The importance of close monitoring of serum urate levels and optimal treatment goals are key points to emphasize. Further, primary care physicians and other providers should be encouraged to consult with a rheumatologist when, even after multiple adjustments to treatment are made, a patient cannot reach urate goals, or continues to experience refractory gout flares. The future of gout patient education must also include the many settings where critical educational opportunities arise. Patients with gout flares in the hospital [24], emergency rooms, and podiatric offices should be educated about long-term prevention as well as the immediate issue of gout flare management.

Optimal disease education and self-management tools for gout patients must consider patient preferences and modalities most effective for them. Online programs may be appropriate for some people, and support and education groups or individualized patient counseling for others. Some will prefer text messages reminders; others may prefer email alerts or phone calls. Different approaches may be needed based on age, educational level, health literacy, gender, ethnicity, language, and other factors which affect ability to access programs. Further research is necessary to look at which patients would benefit from interventions, and identify barriers to access.

Self-management education programs have demonstrated positive impact on self-efficacy, knowledge, recommended behaviors, and pain [26]. Despite this, participation among US adults remains persistently low (especially in patients with less formal education), though attendance is increased when treating providers make direct referrals to these programs [77]. These findings suggest a need to target promotion of appropriate programs and their benefits to physicians as well as to patients.

Given the time constraints of increasingly brief medical encounters, it is challenging to adequately address the complex information required for optimal self-management and then further, to ensure that this information is well understood, reinforced, and retained, with patient concerns and questions appropriately explored. Nurses, physician assistants, nurse practitioners, pharmacists, and nutritionists with relevant specific training in gout management and treatment all play an essential patient counseling role. Social workers should be a part of this multi-disciplinary approach, as they are trained to assess and explore issues around coping with chronic illness 
and treatment, including the financial, social and cultural factors which can impact patients' understanding, decisions, and adherence in a profound way. Effective communication between multiple providers around patient care is also essential to ensure that consistent messages are given to patients, and treatment plans are understood by all clinicians involved [31].

Culture, race, and ethnicity influence patients' trust in asking questions, expressing concerns about management and treatment, and sharing cultural perspectives about illness beliefs and treatments. Providers must initiate and encourage bidirectional discussions about patients' perspective and encourage questions so that education, treatment, and self-management are relevant to the unique circumstances of each patient. Explicitly asking about and incorporating these issues is an important ingredient in building patient-provider trust and rapport. This is a foundational element of patient-focused education and care and has impact on adherence and health outcomes [78].

In spite of effective available treatments for gout, patients continue to have suboptimal outcomes. Ongoing research is needed to identify and evaluate initiatives which can successfully and cost-effectively support patients in their efforts at self-management, using modalities which are relevant and tailored to individual patient needs. Effective gout patient education is a powerful tool in enhancing self-management strategies and, ultimately, can have a significant impact on gout treatment outcomes and patient quality of life.

\section{Compliance with Ethical Standards}

Conflict of Interest Dr. Fields MD reports personal fees from Takeda Pharmaceuticals, personal fees from Horizon Pharmaceuticals, and personal fees from Ironwood Pharmaceuticals, outside the submitted work.

Adena Batterman declares no conflicts of interest.

Human and Animal Rights and Informed Consent This article does not contain any studies with human or animal subjects performed by any of the authors.

Open Access This article is distributed under the terms of the Creative Commons Attribution 4.0 International License (http:// creativecommons.org/licenses/by/4.0/), which permits unrestricted use, distribution, and reproduction in any medium, provided you give appropriate credit to the original author(s) and the source, provide a link to the Creative Commons license, and indicate if changes were made.

\section{References}

Papers of particular interest, published recently, have been highlighted as:

•- Of major importance

1. Cutler DM, Everett W. Thinking outside the pillbox - medication adherence as a priority for health care reform. N Engl J Med. 2010;362(17):1553-5. https://doi.org/10.1056/NEJMp1002305.
2. Dalbeth N, Petrie KJ, House M, Chong J, Leung W, Chegudi R, et al. Illness perceptions in patients with gout and the relationship with progression of musculoskeletal disability. Arthritis Care Res. 2011;63(11):1605-12. https://doi.org/10.1002/acr.20570.

3. Zhu Y, Pandya BJ, Choi HK. Prevalence of gout and hyperuricemia in the US general population: the National Health and Nutrition Examination Survey 2007-2008. Arthritis Rheumatism. 2011;63(10):3136-41. https://doi.org/10.1002/art.30520.

4. Chandratre P, Mallen CD, Roddy E, Liddle J, Richardson J. "You want to get on with the rest of your life": a qualitative study of health-related quality of life in gout. Clin Rheumatol. 2016;35(5): 1197-205. https://doi.org/10.1007/s10067-015-3039-2.

5. Md DB, Andrews LM, Yadao AM, Kahler KH. The effect of gout on health-related quality of life, work productivity, resource use and clinical outcomes among patients with hypertension. Expert Rev Pharmacoecon Outcomes Res. 2012;12:821-9.

6. Spaetgens B, Tran-Duy A, Wijnands JMA, van der Linden S, Boonen A. Health and utilities in patients with gout under the care of a rheumatologist. Arthritis Care Res. 2015;67(8):1128-36. https://doi.org/10.1002/acr.22551.

7. Fisher MC, Rai SK, Lu N, Zhang Y, Choi HK. The unclosing premature mortality gap in gout: a general population-based study. Ann Rheum Dis. 2017;76(7):1289-94. https://doi.org/10.1136/ annrheumdis-2016-210588.

8. Rai SK, Burns LC, De Vera MA, Haji A, Giustini D, Choi HK. The economic burden of gout: a systematic review. Semin Arthritis Rheum. 2015;45(1):75-80. https://doi.org/10.1016/j.semarthrit. 2015.02.004.

9. Doherty M, Jansen TL, Nuki G, Pascual E, Perez-Ruiz F, Punzi L, et al. Gout: why is this curable disease so seldom cured? Ann Rheum Dis. 2012;71(11):1765-70. https://doi.org/10.1136/ annrheumdis-2012-201687.

10. Khanna PP, Perez-Ruiz F, Maranian P, Khanna D. Long-term therapy for chronic gout results in clinically important improvements in the health-related quality of life: short form-36 is responsive to change in chronic gout. Rheumatology (Oxford). 2011;50(4):740 5. https://doi.org/10.1093/rheumatology/keq346.

11. Schumacher HR, Becker MA, Lloyd E, MacDonald PA, Lademacher C. Febuxostat in the treatment of gout: 5-yr findings of the FOCUS efficacy and safety study. Rheumatology (Oxford). 2009;48(2):188-94. https://doi.org/10.1093/rheumatology/ ken457.

12. Hui M, Carr A, Cameron S, Davenport G, Doherty M, Forrester H, et al. The British Society for Rheumatology Guideline for the Management of Gout. Rheumatology (Oxford). 2017;56(7):10569. https://doi.org/10.1093/rheumatology/kex150.

13. Khanna D, Fitzgerald JD, Khanna PP, Bae S, Singh MK, Neogi T, et al. 2012 American College of Rheumatology guidelines for management of gout. Part 1: systematic nonpharmacologic and pharmacologic therapeutic approaches to hyperuricemia. Arthritis Care Res. 2012;64(10):1431-46. https://doi.org/10.1002/acr.21772.

14. Richette P, Doherty M, Pascual E, Barskova V, Becce F, CastañedaSanabria J, et al. 2016 updated EULAR evidence-based recommendations for the management of gout. Ann Rheum Dis. 2017;76(1): 29-42. https://doi.org/10.1136/annrheumdis-2016-209707.

15. Annemans L, Spaepen E, Gaskin M, Bonnemaire M, Malier V, Gilbert T, et al. Gout in the UK and Germany: prevalence, comorbidities and management in general practice 2000-2005. Ann Rheum Dis. 2008;67(7):960-6. https://doi.org/10.1136/ard.2007. 076232 .

16. Juraschek SP, Kovell LC, Miller ER, Gelber AC. Gout, uratelowering therapy, and uric acid levels among adults in the United States. Arthritis Care Res. 2015;67(4):588-92. https://doi.org/10. 1002/acr.22469.

17. Rashid N, Coburn BW, Wu Y, Cheetham TC, Curtis JR, Saag KG, et al. Modifiable factors associated with allopurinol adherence and 
outcomes among patients with gout in an integrated healthcare system. J Rheumatol. 2015;42(3):504-12. https://doi.org/10.3899/ jrheum. 140588 .

18. De Vera MA, Marcotte G, Rai S, Galo JS, Bhole V. Medication adherence in gout: a systematic review. Arthritis Care Res. 2014;66(10):1551-9. https://doi.org/10.1002/acr.22336.

19. Scheepers, Lieke E J M, Onna Mv, Stehouwer CDA, Singh JA, Arts ICW, Boonen A. Medication adherence among patients with gout: a systematic review and meta-analysis. Semin Arthritis Rheum 2017. https://doi.org/10.1016/j.semarthrit.2017.09.007.

20. Ogdie AR, Hoch S, Dunham J, Von Feldt JM. A roadmap for education to improve the quality of care in gout. Curr Opin Rheumatol. 2010;22(2):173-80. https://doi.org/10.1097/BOR. 0b013e328335eee3.

21. Dalbeth N, Choi HK, Terkeltaub R. Review: gout: a roadmap to approaches for improving global outcomes. Arthritis Rheumatol. 2017;69:22-34.

22.• Dalbeth N, Lindsay K. The patient's experience of gout: new insights to optimize management. Curr Rheumatol Rep. 2012;14: 173-8. Outstanding review of the gout experience from the patient's point of view.

23. Coburn BW, Bendlin KA, Sayles H, Hentzen KS, Hrdy MM, Mikuls TR. Target serum urate: do gout patients know their goal? Arthritis Care Res. 2016;68(7):1028-35. https://doi.org/10.1002/ acr.22785.

24. Wright S, Chapman PT, Frampton C, O'Donnell JL, Raja R, Stamp L. Management of gout in a hospital setting: a lost opportunity. J Rheumatol. 2017;44(10):1493-8. https://doi.org/10.3899/jrheum. 170387.

25. Iversen MD, Hammond A, Betteridge N. Self-management of rheumatic diseases: state of the art and future perspectives. Ann Rheum Dis. 2010;69(6):955-63. https://doi.org/10.1136/ard.2010.129270.

26. Lorig K, Lubeck D, Kraines RG, Seleznick M, Holman HR. Outcomes of self-help education for patients with arthritis. Arthritis Rheum. 1985;28(6):680-5. https://doi.org/10.1002/art. 1780280612.

27. Ory MG, Ahn S, Jiang L, Lorig K, Ritter P, Laurent DD, et al. National study of chronic disease self-management: six-month outcome findings. J Aging Health. 2013;25(7):1258-74. https://doi. org/10.1177/0898264313502531.

28. Lindsay K, Gow P, Vanderpyl J, Logo P, Dalbeth N. The experience and impact of living with gout: a study of men with chronic gout using a qualitative grounded theory approach. J Clin Rheumatol. 2011:17:1-6

29. Harrold LR, Mazor KM, Velten S, Ockene IS, Yood RA. Patients and providers view gout differently: a qualitative study. Chronic Illness. 2010;6(4):263-71. https://doi.org/10.1177/1742395310378761.

30. Dow A, Thibault G. Interprofessional education - a foundation for a new approach to health care. N Engl J Med. 2017;377(9):803-5. https://doi.org/10.1056/NEJMp1705665.

31. Morris C, Macdonald L, Stubbe M, Dowell A. "It's complicated"talking about gout medicines in primary care consultations: a qualitative study. BMC Fam Pract. 2016;17(1):114. https://doi.org/10. 1186/s12875-016-0515-y.

32. van Mierlo T, Fournier R, Ingham M. Targeting medication nonadherence behavior in selected autoimmune diseases: a systematic approach to digital health program development. PLoS One. 2015;10(6):e0129364. https://doi.org/10.1371/journal.pone. 0129364 .

33. Ndosi M, Johnson D, Young T, Hardware B, Hill J, Hale C, et al. Effects of needs-based patient education on self-efficacy and health outcomes in people with rheumatoid arthritis: a multicentre, single blind, randomised controlled trial. Ann Rheum Dis. 2016;75(6): 1126-32. https://doi.org/10.1136/annrheumdis-2014-207171.

34. Zangi HA, Ndosi M, Adams J, Andersen L, Bode C, Boström C, et al. EULAR recommendations for patient education for people with inflammatory arthritis. Ann Rheum Dis. 2015;74(6):954-62. https://doi.org/10.1136/annrheumdis-2014-206807.

35. Zhang LY, Schumacher HR, Su HH, Lie D, Dinnella J, Baker JF, et al. Development and evaluation of a survey of gout patients concerning their knowledge about gout. J Clin Rheumatol. 2011;17(5):242-8. https://doi.org/10.1097/RHU.0b013e318228b4e2.

36. Harrold LR, Mazor KM, Peterson D, Naz N, Firneno C, Yood RA. Patients' knowledge and beliefs concerning gout and its treatment: a population based study. BMC Musculoskelet Disord. 2012;13(1): 180. https://doi.org/10.1186/1471-2474-13-180.

37. Spaetgens B, Pustjens T, Scheepers L, Janssens H, van der Linden $\mathrm{S}$, Boonen A. Knowledge, illness perceptions and stated clinical practice behaviour in management of gout: a mixed methods study in general practice. Clin Rheumatol. 2016;35(8):2053-61. https:// doi.org/10.1007/s10067-016-3212-2.

38. Richardson JC, Liddle J, Mallen CD, Roddy E, Prinjha S, Ziebland S, et al. "Why me? I don't fit the mould ... I am a freak of nature": a qualitative study of women's experience of gout. BMC Womens Health. 2015;15(1):122. https://doi.org/10.1186/s12905-015-0277-z.

39. Rifaat A, Batterman A, Horton R, Fields TR. Developing a gout needs assessment incorporating patient perspective on self-management, self-efficacy and disease specific knowledge, to inform a patient education initiative. ACR meeting abstracts. [abstract]. Arthritis Rheumatol. 2016;68(suppl 10). http://acrabstracts.org/ abstract/developing-a-gout-needs-assessment-incorporatingpatient-perspective-on-self-management-self-efficacy-and-diseasespecific-knowledge-to-inform-a-patient-education-initiative.

40. Weinberger SE, Johnson BH, Ness DL. Patient- and familycentered medical education: the next revolution in medical education? Ann Intern Med. 2014;161(1):73-5. https://doi.org/10.7326/ M13-2993.

41. Duyck SD, Petrie KJ, Dalbeth N. "You don't have to be a drinker to get gout, but it helps": a content analysis of the depiction of gout in popular newspapers. Arthritis Care Res. 2016;68(11):1721-5. https://oi.org/10.1002/acr.22879.

42. Spencer K, Carr A, Doherty M. Patient and provider barriers to effective management of gout in general practice: a qualitative study. Ann Rheum Dis. 2012;71:1490-5.

43. Vaccher S, Kannangara DRW, Baysari MT, Reath J, Zwar N, Williams KM, et al. Barriers to care in gout: from prescriber to patient. J Rheumatol. 2016;43:144-9.

44. Kirwan JR, Tugwell PS. Overview of the patient perspective at OMERACT 10 - conceptualizing methods for developing patientreported outcomes. J Rheumatol. 2011;38(8):1699-701. https://doi. org/10.3899/jrheum. 110388 .

45. Singh JA, Taylor WJ, Simon LS, Khanna PP, Stamp LK, McQueen FM, et al. Patient-reported outcomes in chronic gout: a report from OMERACT 10. J Rheumatol. 2011;38(7):1452-7. https://doi.org/ 10.3899/jrheum.110271.

46. Khanna P, Berrocal V, Hays T, Clauw DJ, Williams DA. Focus groups reveal knowledge gaps in patients with gout-a qualitative study. ACR Meeting Abstracts. 2012. http://acrabstracts.org/ abstract/focus-groups-reveal-knowledge-gaps-in-patients-withgout-a-qualitative-study/

47. Treharne GJ, Richardson AC, Neha T, Fanning N, Janes R, Hudson $\mathrm{B}$, et al. Education preferences of people with gout: exploring differences between indigenous and non-indigenous peoples from rural and urban locations. Arthritis Care Res. 2017. https://doi.org/10. 1002/acr.23272.

48. Krishnan E, Lienesch D, Kwoh CK. Gout in ambulatory care settings in the United States. J Rheumatol. 2008;35:498-501.

49. Krishnan E. Gout in African Americans. Am J Med. 2014;127(9): 858-64. https://doi.org/10.1016/j.amjmed.2014.03.039.

50. Singh JA. Facilitators and barriers to adherence to urate-lowering therapy in African-Americans with gout: a qualitative study. 
Arthritis Res Ther. 2014;16(2):R82. https://doi.org/10.1186/ ar4524.

51. Singh JA. The impact of gout on patient's lives: a study of AfricanAmerican and Caucasian men and women with gout. Arthritis Res Ther. 2014;16(3):R132. https://doi.org/10.1186/ar4589.

52. Johnson RL, Roter D, Powe NR, Cooper LA. Patient race/ethnicity and quality of patient-physician communication during medical visits. Am J Public Health. 2004;94(12):2084-90. https://doi.org/ 10.2105/AJPH.94.12.2084.

53. Humphrey C, Hulme R, Dalbeth N, Gow P, Arroll B, Lindsay K. A qualitative study to explore health professionals' experience of treating gout: understanding perceived barriers to effective gout management. J Prim Health Care. 2016;8(2):149-56. https://oi. org/10.1071/HC15017.

54. Flurey C, Hewlett S, RODHAM K, White A, Noddings R, Kirwan J. Coping strategies, psychological impact and support preferences of men with rheumatoid arthritis: a multicentre survey. Arthritis Care Res 2017. https://doi.org/10.1002/acr.23422.

55. Johnston ME, Treharne GJ, Chapman PT, Stamp LK. Patient information about gout: an international review of existing educational resources. J Rheumatol. 2015;42(6):975-8. https://doi.org/10.3899/ jrheum.141442.

56. Robinson PC, Schumacher HR. A qualitative and quantitative analysis of the characteristics of gout patient education resources. Clin Rheumatol. 2013;32(6):771-8. https://doi.org/10.1007/s10067013-2168-8.

57. Lawrence Edwards N, Malouf R, Perez-Ruiz F, Richette P, Southam S, DiChiara M. Computational lexical analysis of the language commonly used to describe gout. Arthritis Care Res. 2016;68(6):763-8. https://doi.org/10.1002/acr.22746.

58. Jimenez-Liñan LM, Edwards L, Abhishek A, Doherty M. Adequacy of online patient information resources on gout and potentially curative urate-lowering treatment. Arthritis Care Res. 2017;69(5):748-52. https://doi.org/10.1002/acr.22981.

59. Nguyen AD, Baysari MT, Kannangara DRW, Tariq A, Lau AYS, Westbrook JI, et al. Mobile applications to enhance selfmanagement of gout. Int J Med Inform. 2016;94:67-74. https:// doi.org/10.1016/j.ijmedinf.2016.06.021.

60. Vervloet M, Linn AJ, Van Weert JCM, Bakker DH, Bouvy ML, Dijk LV. The effectiveness of interventions using electronic reminders to improve adherence to chronic medication: a systematic review of the literature. J Am Med Inform Assoc. 2012;19(5):696704. https://doi.org/10.1136/amiajnl-2011-000748.

61. Galo JS, Mehat P, Rai SK, Avina-Zubieta A, De Vera MA. What are the effects of medication adherence interventions in rheumatic diseases: a systematic review. Ann Rheum Dis. 2016;75:667-73.

62. Nasser-Ghodsi N, Harrold LR. Overcoming adherence issues and other barriers to optimal care in gout. Curr Opin Rheumatol. 2015;27(2): 134-8. https://doi.org/10.1097/BOR.000000000000141.

63. Goldfien R, Pressman A, Jacobson A, Ng M, Avins A. A pharmacist-staffed, virtual gout management clinic for achieving target serum uric acid levels: a randomized clinical trial. Permanente J. 2016;20:18. https://doi.org/10.7812/TPP/15-234.

64. Mikuls TR, Cheetham T, Levy GD, Rashid N, Low K, Coburn BW, Saag K, Chen L, Curtis JR. Improving gout outcomes: the randomized evaluation of an ambulatory care pharmacist-led intervention to optimize urate lowering pathways (RAmP-Up) study [abstract]. Arthritis Rheumatol. 2017;69(suppl 10). http://acrabstracts.org/ abstract/improving-gout-outcomes-the-randomized-evaluation-of- an-ambulatory-care-pharmacist-led-intervention-to-optimize-uratelowering-pathways-ramp-up-study.

65.• Rees F, Jenkins W, Doherty M. Patients with gout adhere to curative treatment if informed appropriately: proof-of-concept observational study. Ann Rheum Dis. 2013;72:826-30. Important finding of excellent outcomes with strong nurse-led gout education program.

66. Abhishek A, Jenkins W, La-Crette J, Fernandes G, Doherty M. Long-term persistence and adherence on urate-lowering treatment can be maintained in primary care-5-year follow-up of a proof-ofconcept study. Rheumatology (Oxford). 2017;56(4):529-33. https://doi.org/10.1093/rheumatology/kew395.

67. Larsson I, Arvidsson S, Bergman S, Arvidsson B. Patients' perceptions of drug information given by a rheumatology nurse: a phenomenographic study. Musculoskeletal Care. 2010;8(1):3645. https://doi.org/10.1002/msc.164.

68. Fields TR, Rifaat A, Yee AMF, Ashany D, Kim K, Tobin M, et al. Pilot study of a multidisciplinary gout patient education and monitoring program. Semin Arthritis Rheum. 2016;46:601-8. https:// doi.org/10.1016/j.semarthrit.2016.10.006.

69. Lorig K, Gonzalez VM, Ritter P. Community-based Spanish language arthritis education program: a randomized trial. Med Care. 1999;37(9):957-63. https://doi.org/10.1097/00005650199909000-00011.

70. Grønning K, Midttun L, Steinsbekk A. Patients' confidence in coping with arthritis after nurse-led education; a qualitative study. BMC Nurs. 2016;15(1):28. https://doi.org/10.1186/s12912-016-0150-x.

71. Dures E, Kitchen K, Almeida C, Ambler N, Cliss A, Hammond A, et al. "They didn't tell us, they made us work it out ourselves": patient perspectives of a cognitive-behavioral program for rheumatoid arthritis fatigue. Arthritis Care Res (Hoboken). 2012;64(4): 494-501. https://doi.org/10.1002/acr.21562.

72. Buchbinder R, Hall S, Youd JM. Functional health literacy of patients with rheumatoid arthritis attending a community-based rheumatology practice. J Rheumatol. 2006;33:879-86.

73. Barton JL, Trupin L, Tonner C, Imboden J, Katz P, Schillinger D, et al. English language proficiency, health literacy, and trust in physician are associated with shared decision making in rheumatoid arthritis. J Rheumatol. 2014;41(7):1290-7. https://doi.org/10. 3899/jrheum.131350.

74. Ha Dinh TT, Bonner A, Clark R, Ramsbotham J, Hines S. The effectiveness of the teach-back method on adherence and selfmanagement in health education for people with chronic disease: a systematic review. JBI Database Syst Rev Implement Rep. 2016;14:210-47.

75. Kelley P, Whatson T. Making long-term memories in minutes: a spaced learning pattern from memory research in education. Front Hum Neurosci. 2013;7:589.

76. Seewoodharry MD, Maconachie GDE, Gillies CL, Gottlob I, McLean RJ. The effects of feedback on adherence to treatment: a systematic review and meta-analysis of RCTs. Am J Prev Med. 2017;53(2):232-40. https://doi.org/10.1016/j.amepre.2017.03.005.

77. Murphy LB, Brady TJ, Boring MA, Theis KA, Barbour KE, Qin J, et al. Self-management education participation among US adults with arthritis: who's attending? Arthritis Care Res. 2017;69(9): 1322-30. https://doi.org/10.1002/acr.23129.

78. Zolnierek KBH, Dimatteo MR. Physician communication and patient adherence to treatment: a meta-analysis. Med Care. 2009;47(8):82634. https://doi.org/10.1097/MLR.0b013e31819a5acc. 